\title{
Effectiveness of mailed letters to improve medication adherence among Medicare Advantage Plan participants with chronic conditions
}

This article was published in the following Dove Medical Press journal: Patient Preference and Adherence

\author{
Amanda Mann' \\ Tara W Esse ${ }^{2}$ \\ Omar Serna ${ }^{2}$ \\ Liana D Castel ${ }^{3,4}$ \\ Susan M Abughosh ${ }^{5}$ \\ 'Cigna-HealthSpring, Houston, \\ TX, USA; ${ }^{2}$ CareAllies, Houston, \\ TX, USA $;{ }^{3}$ Cigna Health and Life \\ Insurance Company, Raleigh, NC, \\ USA; ${ }^{4}$ Lundy-Fetterman School of \\ Business, Campbell University, Buies \\ Creek, NC, USA; ${ }^{5}$ Department of \\ Pharmaceutical Health Outcomes and \\ Policy, University of Houston College \\ of Pharmacy, Houston, TX, USA
}

Background: Medication adherence is associated with improved health outcomes in multiple chronic diseases. Information is needed on the effectiveness of specific adherence interventions. This study's objectives were to quantify effects of a targeted mailing intervention on adherence among older adults at risk for nonadherence, and to examine associations of individual and plan characteristics with adherence.

Materials and methods: Among adults enrolled in a Medicare Advantage Plan with prescription drug coverage from May 2014 to June 2015, those identified as eligible for the mailing intervention had a late refill for oral antidiabetic medication, statin, angiotensin-converting enzyme inhibitor, or angiotensin receptor blocker medication and were previously unreachable by telephone. Pharmacy claims data were analyzed with the outcome of 6-month proportion of days covered (PDC) before and after the mailing. The $t$-test and chi-square analyses were used to evaluate univariate associations. Multivariable linear and logistic regression models were conducted to assess relative covariate effects. A sub-analysis of those with at least one medication fill post-mailing was also performed.

Results: A total of 460 non-adherent individuals aged $70 \pm 10.5$ years, with $50.2 \%$ female and $66.7 \%$ white individuals, were included. Of those who were mailed a letter, $24.1 \%$ became adherent to the specified maintenance medication. Those who received $>30$-day supplies were more than twice as likely to become adherent after the mailed letter than those who received 30-day supplies or less $(P<0.05)$. Baseline higher PDC was also associated with greater adherence post-mailing $(P<0.01)$. A total of $284(61.7 \%)$ individuals filled their medication at least once after the mailed letter; of those, 39.1\% became adherent (mean [SD] change in $\mathrm{PDC}=0.15[ \pm 0.28])$

Conclusion: Our findings suggest that a single mailed letter improved medication adherence by $24.1 \%$ in adults with chronic conditions. As a health plan seeking to improve its customers' well-being and outcomes, Cigna continues to utilize targeted mail interventions to improve medication adherence.

Keywords: patient compliance, chronic disease, managed care programs, Medicare, Medicare Part D, Medicare Part C, mail distributions, population health, program evaluation

\section{Introduction}

Medication adherence has been associated with improved health outcomes in multiple chronic disease states, including reduced health care utilization and mortality. ${ }^{1-3}$ Despite the increased medication costs incurred by adherence, larger savings are realized through decreased hospital inpatient and emergency department use ${ }^{4}$ all-cause medical costs have been shown to be lower in adherent patients with diabetes, hypertension,
Correspondence: Liana D Castel Lundy-Fetterman School of Business, Campbell University, Buies Creek, North Carolina, USA

Tel +l 8049043549

Email liana.castel@cigna.com
Patient Preference and Adherence 2019:13 37-46

37 
and hypercholesterolemia. ${ }^{5}$ Improving medication adherence to diabetes medication(s) alone could provide a $\$ 4.7$ billion annual cost savings. ${ }^{6}$ The positive effects and importance of medication adherence are especially emphasized in populations of older adults.

Medicare is the federally-funded United States insurance program for adults aged $\geq 65$ years. The Centers for Medicare and Medicaid Services (CMS) incorporates medication adherence into their Star Ratings. ${ }^{7}$ These ratings are used to standardize and compare prevention, satisfaction, and treatment metrics in order to evaluate and compare health plan performance nationally (http:/healthinsuranceratings. ncqa.org). Adherence measures that comprise the ratings include oral antidiabetic medication(s), statin medication, and angiotensin-converting enzyme inhibitor (ACEI) or angiotensin receptor blocker (ARB) medication. While the importance of medication adherence has been increasingly promoted, recent studies show that medication nonadherence remains a significant problem and can be as high as $49.1 \%$ in those with chronic conditions. ${ }^{8}$

In their 2018 study, Easthall et al identified patientlevel barriers to adherence in prevention of cardiovascular disease and mapped these factors to a conceptual framework designed to create tailored behavioral change. ${ }^{9}$ Health plans with an interest in prevention have taken on the role of partnering with individuals to promote healthy behaviors through behavioral health benefits like telephonic coaching, and helping to better manage disease through pharmacy benefits management programs. In-person patient counseling has been shown to increase adherence, lower blood hemoglobin A1c levels in patients with diabetes, and lower low-density lipoprotein cholesterol in coronary artery disease patients. ${ }^{10,11}$ One literature review concluded that while pharmacy interventions can improve medication adherence, when the intervention stops, so do the effects on adherence. ${ }^{12}$ Health plans are well positioned to influence medication adherence, and to manage prevention and treatment at the system, provider, and individual levels.

Identifying system-level modifiable factors associated with medication adherence may allow more effective interventions to be developed in the future. In a US veteran population, Watanabe et al observed that new users of statin without a copayment were more adherent than their counterparts with a copayment. ${ }^{13}$ Those utilizing home delivery have been shown to have higher adherence rates than those utilizing retail pharmacies. ${ }^{14}$ Managed care organizations, such as Medicare Advantage, primarily utilize telephonic and mail interventions to reach their participants. While some studies have shown that pharmacy telephonic interventions have greater improvement in adherence than mail interventions, ${ }^{15,16}$ a randomized controlled trial found no difference in adherence to osteoporosis medication when comparing a telephone-based counseling intervention to a control group in a Medicare population. ${ }^{17}$ While mailed letters to physicians along with plan members have been shown to increase medication adherence, ${ }^{18,19}$ the intervention of letters mailed only to plan members has not been assessed. It is clear from past research that to be effective, such programs should not rely on one mode of communication (eg, phone-only), and take a "multimodal" contact approach consisting of more than one means of outreach (eg, e-mail, mail, and phone) to improve adherence. ${ }^{20}$

The goal of this study was to quantify the impact on adherence of mailed letters, among a targeted Medicare Advantage population at risk for nonadherence and unreachable by phone. Eligible individuals were identified if they were late to refill their chronic disease management medications. If they could not be contacted by telephone, a letter specifying the medication that needed to be refilled was mailed to the address on file. Evaluating the effectiveness of these mailed letters on improving the proportion of days covered (PDC) rate and examining both modifiable and static factors influencing adherence may allow future interventions to be more effective in targeting at-risk individuals and improving overall PDC rates in the Medicare population.

\section{Materials and methods Study design and selection}

The study protocol was reviewed and approved by the University of Houston Institutional Review Board. A retrospective pre-post study was performed on adults enrolled in a Medicare Advantage Plan with prescription drug coverage from May 2014 to June 2015. Individuals must have been continuously enrolled in the health plan throughout the measurement period, and eligible to receive an adherencefocused letter via mail within November and December 2014 as part of the Medicare Advantage Plan's adherence program. Mailing eligibility criteria included having received (per pharmacy claims) a prescription for a statin medication, ACEI or ARB medication, or oral antidiabetic medication in the year 2014, and having been late picking up their refill. The letters were mailed if the individual did not answer a phone call from a pharmacy representative within three phone call attempts or was otherwise unreachable by phone. The letters contained individually tailored information including 
name, medication name (or names compiled through mail merge if they were behind on more than one medication), last date medication was filled, name and phone number of the pharmacy from which they last picked up the medication, a general statement of the importance of taking prescribed medication and adhering to prescriber recommendations, and the health plan regional Medical Director name and contact number for questions.

An initial total of 541 individuals were eligible for prescreening, in which phase letters were not sent if there had not been at least two fills of the specified medication in the year $2014(n=14)$, or if the individual was adherent to the specified medication, defined as PDC $>0.8$, before the letter was sent $(n=67)$. In total, 460 letters were sent. Selection criteria are illustrated in Figure 1.

\section{Study variables and outcome measures}

Letters were written in the preferred language designated by the recipient (English or Spanish). Demographic characteristics were included to ensure representativeness and generalizability of the findings, account for possible confounding, and assist targeting future interventions; these factors included age, gender, self-reported ethnicity, and low income subsidy eligibility, which were obtained from the customer benefits database. Region was classified as West Texas (areas Northwest, Southwest, and West of the Houston metropolitan area), East Texas (areas Northeast, Southeast, East, and including the Houston metropolitan area), or Not in Texas, based on residence zip code.
Medication characteristics were obtained from the pharmacy benefits management database. The specified medications in the letters were identified via National Drug Code numbers. Medication category was denoted as statin, ACEI or ARB, or oral antidiabetic. Brand or generic was denoted based on the medication name specified in the sent letter. Day supply, copay, the pharmacy at which the medication was filled at, and the fill history of the specified medication was also obtained. The day supply, copay, and pharmacy information were identified based on a claim for the specified medication's fill just prior to the letter being sent. Copay was defined as the out-of-pocket expense to the customer for the medication. Pharmacy type was classified as either retail or mail-order pharmacy.

Outcomes were also obtained and calculated from the pharmacy benefits management database. PDC was chosen as the outcome measure for its documented correlation with other adherence measures. ${ }^{21,22} \mathrm{~A}$ threshold of $\mathrm{PDC} \geq 0.8$ is commonly used to denote dichotomous adherence in extant studies, ${ }^{1,23-25}$ and is used in the Medicare Star Ratings benchmarking program to compare health plans and providers. Initial PDC rate was calculated from pharmacy claims data 6 months prior to the date the letter was sent. Final PDC was calculated from pharmacy claims data 6 months after the date the letter was sent. Change in PDC was calculated as the difference between initial and final PDC. The primary outcome of adherence was defined as a final PDC $\geq 0.8$. Individuals were considered to have filled their medication after the letter was sent if there was at least one pharmacy claim for

Medicare Advantage program participants with prescription drug coverage from May 2014 to June 2015 who had received a prescription for a statin medication, ACEI or ARB medication, or oral antidiabetic medication in the year 2014, and were late picking up their refill $(\mathrm{N}=514)$

Excluded

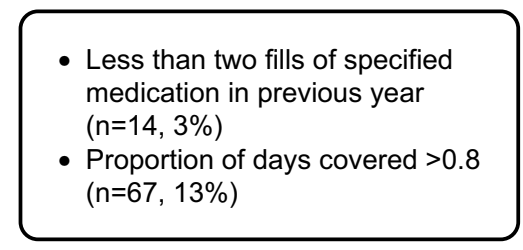

Sub-analysis

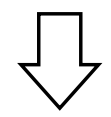

Included

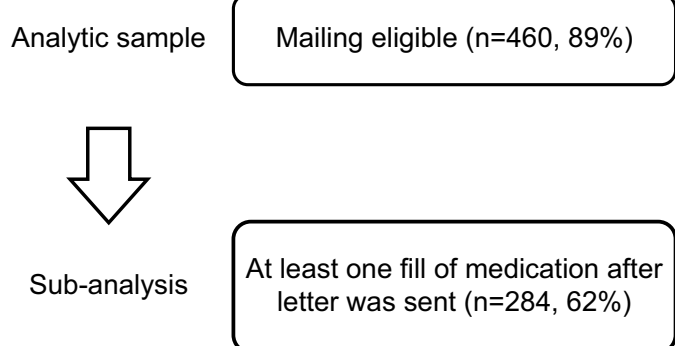

Figure I Customer selection flowchart.

Abbreviations: $A C E I$, angiotensin-converting enzyme inhibitor; $A R B$, angiotensin receptor blocker. 
the specified medication in the 6 months after the letter was sent. Days before the next fill of the specified medication were calculated based on the date the letter was sent and the pharmacy claims data.

\section{Statistical analysis}

Chi-square proportion tests and Student's $t$-tests were conducted to describe univariate relationships between adherence and individual and medication characteristics. A Fisher's exact test was used to compare proportions of the population with $\mathrm{PDC} \geq 0.8$ before and after the mailing. A sub-analysis of 284 individuals who filled the specified medication at least once after the letter was sent was performed to analyze those who did not likely discontinue the medication class or switch to another medication within-class.

Two regression models were built to evaluate patient characteristics associated with better adherence among the patients who received the letters, as adherence is best measured using more than one outcome variable. A multiple linear regression analysis was conducted with an outcome of change in PDC (Table 1). Independent variables included medication type and individual characteristics. A multiple logistic regression analysis with the same independent variables was also carried out with an adherence outcome defined as a final PDC $\geq 0.8$ (Table 2). The days' supply variable was dichotomous (30 or fewer days' supply vs $>30$ days' supply) for both the linear and logistic regression models. Multiple regression was also used to analyze the subset of 284 individuals who filled the specified medication at least once after the mailed letter was analyzed (Tables S1 and S2). All statistical analyses were performed utilizing SAS Version 9.3 (SAS Institute Inc., Cary, NC, USA).

Table I Linear regression analysis of change in 6-month PDC before vs after the mailed letter

\begin{tabular}{l|l|l}
\hline & Beta (standard error) & $P$-value \\
\hline Language of letter & $-0.050(0.048)$ & 0.299 \\
Age & $-0.004(0.002)$ & 0.041 \\
Gender & $-0.044(0.037)$ & 0.238 \\
Ethnicity & $-0.019(0.023)$ & 0.410 \\
Region & $0.027(0.029)$ & 0.342 \\
Low income subsidy eligibility & $0.024(0.040)$ & 0.553 \\
Medication category & $0.010(0.026)$ & 0.693 \\
Generic vs brand & $0.033(0.086)$ & 0.701 \\
Day supply & $0.123(0.039)$ & 0.002 \\
Copay & $-0.002(0.002)$ & 0.180 \\
Pharmacy type & $0.020(0.121)$ & 0.872 \\
\hline
\end{tabular}

Abbreviation: PDC, proportion of days covered.
Table 2 Logistic regression analysis of adherence defined as 6-month PDC of at least $80 \%$ after the mailed letter

\begin{tabular}{|c|c|c|}
\hline & OR $(95 \% \mathrm{Cl})$ & $P$-value \\
\hline \multicolumn{3}{|l|}{ Language of letter } \\
\hline English & Reference & Reference \\
\hline Spanish & $0.739(0.383-1.426)$ & 0.368 \\
\hline \multicolumn{3}{|l|}{ Age } \\
\hline Age, years & $0.994(0.972-1.016)$ & 0.594 \\
\hline \multicolumn{3}{|l|}{ Gender } \\
\hline Female & Reference & Reference \\
\hline Male & $0.968(0.615-1.524)$ & 0.888 \\
\hline \multicolumn{3}{|l|}{ Ethnicity } \\
\hline White & Reference & Reference \\
\hline Hispanic & $0.673(0.323-1.402)$ & 0.291 \\
\hline African-American & $1.008(0.538-1.888)$ & 0.981 \\
\hline Asian & $1.049(0.185-5.937)$ & 0.957 \\
\hline \multicolumn{3}{|l|}{ Region of Texas } \\
\hline Out of Texas & Reference & Reference \\
\hline West & I.359 (0.338-5.47I) & 0.666 \\
\hline East & $1.563(0.40 \mathrm{I}-6.09 \mathrm{I})$ & 0.520 \\
\hline \multicolumn{3}{|c|}{ Low income subsidy eligibility } \\
\hline No & Reference & Reference \\
\hline Yes & $1.189(0.725-1.951)$ & 0.492 \\
\hline \multicolumn{3}{|l|}{ Medication category } \\
\hline Statin & Reference & Reference \\
\hline ACEI/ARB & $0.649(0.396-1.061)$ & 0.085 \\
\hline Oral antidiabetic & $0.777(0.406-1.489)$ & 0.447 \\
\hline \multicolumn{3}{|l|}{ Generic vs brand } \\
\hline Generic & Reference & Reference \\
\hline Brand & $0.773(0.262-2.28 I)$ & 0.641 \\
\hline \multicolumn{3}{|l|}{ Day supply } \\
\hline 30 days or less & Reference & Reference \\
\hline$>30$ days & $2.198(1.307-3.696)$ & 0.003 \\
\hline \multicolumn{3}{|l|}{ Copay } \\
\hline Copay, $\$$ & $0.994(0.973-1.016)$ & 0.587 \\
\hline \multicolumn{3}{|l|}{ Pharmacy type } \\
\hline Retail & Reference & Reference \\
\hline Mail order & $1.028(0.254-4.159)$ & 0.969 \\
\hline \multicolumn{3}{|l|}{ Initial PDC } \\
\hline PDC & $39.283(2.764-558.363)$ & 0.007 \\
\hline
\end{tabular}

Abbreviations: $A C E I$, angiotensin-converting enzyme inhibitor; $A R B$, angiotensin receptor blocker; PDC, proportion of days covered.

\section{Results}

Table 3 shows that while $40 \%$ (140/349) of the non-adherent participants had medication supply of 30 days or fewer, only $30(27 \%)$ of the 111 adherent participants had supply of 30 days or less. Initial PDC was also higher among adherent vs non-adherent participants (mean $=0.54$ vs $0.51, P=0.013$ ).

Of the 460 non-adherent participants who were mailed letters, $111(24.1 \%)$ became adherent after the mailed letter (Fisher's exact test $<0.001)$ and the mean $( \pm$ SD) change in PDC was $-0.10( \pm 0.40)$. The mean (SD) age of the participants was $69.98( \pm 10.48)$ years, with $50.2 \%$ female and $66.7 \%$ self-reported as white race individuals. Univariate chi-square and Student's $t$-test comparisons among categories 
Table 3 Baseline Medicare Advantage Plan participant and medication characteristics ${ }^{\mathrm{a}}$

\begin{tabular}{|c|c|c|c|c|}
\hline & n (\%) & $\begin{array}{l}\text { Not adherent } \\
\text { at final, } \mathbf{n}(\%)\end{array}$ & $\begin{array}{l}\text { Adherent at } \\
\text { final, } n(\%)\end{array}$ & $P$-value \\
\hline Language of letter & & & & $0.216^{\mathrm{b}}$ \\
\hline English & $362(78.7)$ & $270(74.6)$ & $92(25.4)$ & \\
\hline Spanish & $98(2 \mid .3)$ & $79(80.6)$ & $19(19.4)$ & \\
\hline Age & & & & $0.676^{c}$ \\
\hline Age, years & $70.0 \pm 10.5$ & $70.1 \pm 10.7$ & $69.6 \pm 9.9$ & \\
\hline Gender & & & & $0.784^{b}$ \\
\hline Female & $23 \mid(50.2)$ & I $74(75.3)$ & $57(24.7)$ & \\
\hline Male & $229(49.8)$ & $175(76.4)$ & $54(23.6)$ & \\
\hline Ethnicity & & & & $0.602^{b}$ \\
\hline White & $307(66.7)$ & $232(75.6)$ & $75(24.4)$ & \\
\hline Hispanic & $66(14.4)$ & $54(81.8)$ & $12(18.2)$ & \\
\hline African-American & $80(17.4)$ & $58(72.5)$ & $22(27.5)$ & \\
\hline Asian & $7(1.5)$ & $5(71.4)$ & $2(28.6)$ & \\
\hline Region & & & & $0.576^{\mathrm{b}}$ \\
\hline Out of Texas & $16(3.5)$ & $13(8 \mid .3)$ & $3(18.8)$ & \\
\hline West Texas & $221(48.1)$ & $|7|(77.4)$ & $50(22.6)$ & \\
\hline East Texas & $223(48.5)$ & $165(74.0)$ & $58(26.0)$ & \\
\hline Low Income subsidy eligibility & & & & $0.575^{\mathrm{b}}$ \\
\hline No & $222(48.3)$ & |7| (77.0) & $51(23.0)$ & \\
\hline Yes & $238(51.7)$ & $178(74.8)$ & $60(25.2)$ & \\
\hline Medication category & & & & $0.223^{b}$ \\
\hline Statin & $196(42.6)$ & |4| (7|.9) & $55(28.1)$ & \\
\hline ACEI/ARB & $189(41.1)$ & $150(79.4)$ & $39(20.6)$ & \\
\hline Oral antidiabetic & $75(16.3)$ & $58(77.3)$ & $17(22.7)$ & \\
\hline Generic vs brand & & & & $0.655^{\mathrm{b}}$ \\
\hline Generic & 431 (93.7) & $326(75.6)$ & $105(24.4)$ & \\
\hline Brand & $29(6.3)$ & $23(79.3)$ & $6(20.7)$ & \\
\hline Day supply & & & & $0.013^{b}$ \\
\hline 30 days or less & $170(37.0)$ & I 40 (82.4) & $30(17.7)$ & \\
\hline$>30$ days & $290(63.0)$ & $209(72.1)$ & $81(27.9)$ & \\
\hline Copay & & & & $0.782^{c}$ \\
\hline Copay, $\$$ & $4.36 \pm 12.64$ & $4.45 \pm|3.4|$ & $4.07 \pm 9.89$ & \\
\hline Pharmacy type & & & & $0.805^{b}$ \\
\hline Retail & $449(97.6)$ & $34 \mid(76.0)$ & $108(24.1)$ & \\
\hline Mail order & II (2.4) & $8(72.7)$ & $3(27.3)$ & \\
\hline Initial PDC & & & & $0.013^{c}$ \\
\hline PDC & $0.5 I \pm 0.11$ & $0.51 \pm 0.12$ & $0.54 \pm 0.09$ & \\
\hline
\end{tabular}

Notes: a Values represent mean \pm SD for age, copay, and initial PDC. ${ }^{b}$ Chi-squared test. ${ }^{c} t-T e s t$.

Abbreviations: ACEI, angiotensin-converting enzyme inhibitor; ARB, angiotensin receptor blocker; PDC, proportion of days covered.

for the outcome of adherence are reported in Table 3. The medications specified in the letter were primarily for generics (93.7\%) and were comprised of statins (42.6\%), ACEIs or ARBs (41.1\%), and oral antidiabetic medications (16.3\%). Those who filled more than 30 days of medication at a time were more likely to become adherent after the mailed letter than those who filled a 30-day supply or less (chi-square $P=0.013)$. Also, the mean (SD) initial PDC was $0.51( \pm 0.11)$ and there was a significant difference in initial PDC between those who became adherent after the mailed letter and those who did not (Student's $t$-test, $P=0.013$ ).

A total of 284 (61.7\%) participants filled the specified medication at least once after the mailed letter. Adherence data for this subset along with the overall cohort are reported in Table 4. Of this subset, $39.1 \%$ became adherent after the letter was mailed and the mean (SD) change in PDC was $0.15( \pm 0.28)$. There was a mean $(\mathrm{SD})$ of $39.01( \pm 42.58)$ days before the next fill after the date the letter was mailed.

The multiple linear regression results for the outcome of change in PDC are presented in Table 1 for the whole cohort. Days' supply was found to be significantly associated with change in PDC ( $\beta$ standard error $[\mathrm{SE}]=0.12(0.04), P=0.002)$. Also, age was significantly associated with a small decrease in $\mathrm{PDC}(\beta[\mathrm{SE}]=-0.004$ [0.002], $P=0.041)$. Medication category was not significantly associated with change in PDC in this model. 
Table 4 PDC rates and adherence data ${ }^{\mathrm{a}}$

\begin{tabular}{|c|c|c|c|}
\hline \multicolumn{2}{|l|}{ Total sample } & \multicolumn{2}{|c|}{$\begin{array}{l}\text { Participants with one or more medication fill after the letter } \\
\text { was sent }\end{array}$} \\
\hline Total letters (n) & 460 & Total letters (n) & 284 \\
\hline Initial PDC (mean \pm SD) & $0.5 I \pm 0.1 I$ & Initial PDC (mean \pm SD) & $0.52 \pm 0.11$ \\
\hline Final PDC (mean \pm SD) & $0.4 I \pm 0.39$ & Final PDC (mean $\pm S D)$ & $0.67 \pm 0.28$ \\
\hline Change in PDC (mean $\pm S D$ ) & $-0.10 \pm 0.40$ & Change in PDC (mean \pm SD) & $0.15 \pm 0.28$ \\
\hline Adherent at final, n (\%) & & Adherent at final, n (\%) & \\
\hline No & $349(75.9)$ & No & $60.9(173)$ \\
\hline Yes & III (24.I) & Yes & 39.1 (III) \\
\hline Filled after letter, \% (n) & & Days before next fill & \\
\hline No & $38.5(176)$ & & 39.01 \\
\hline Yes & $61.7(284)$ & & 42.58 \\
\hline
\end{tabular}

Note: a Values represent mean \pm SD for initial PDC, final PDC, change in PDC, and days before next fill.

Abbreviation: PDC, proportion of days covered.

The multiple logistic regression results for the outcome of adherence after the mailed letter with a C-statistic of 0.63 are displayed in Table 2 for the entire cohort. Those who filled a $>30$-day supply of medication at a time had increased adherence after the mailed letter, compared to those who filled less than a 30-day supply (OR $=2.2 ; 95 \%$ $\mathrm{CI}=1.3-3.7 ; P=0.003)$. Initial $\mathrm{PDC}$ was also significantly associated with becoming adherent after the mailed letter ( $\mathrm{OR}=39.3 ; 95 \% \mathrm{CI}=2.8-558.4 ; P=0.007)$. Neither age nor medication type (statin medications vs ACEIs or ARBs) was significantly associated with adherence improvements in the multivariable model.

Tables S1 and S2 report multiple regression analyses of the subset who filled the specified medication at least once after the mailed letter. Initial PDC was not assessed in these analyses. Days' supply was found to be associated positively with change in PDC within this model $(\beta[\mathrm{SE}]=0.14$ [0.034]; $P<0.001)$. Also, in the subset, Texas vs out-of-state geographic region was associated with change in PDC ( $\beta[\mathrm{SE}]=0.045$ [0.022]; $P=0.045)$. The multiple logistic regression results for the outcome of adherence had a C-statistic of 0.745 . Days' supply $>30$ days at baseline was associated with greater adherence compared to those with a 30-day supply or less ( $\mathrm{OR}=2.743 ; 95 \% \mathrm{CI}=1.514-4.970$; $P=0.001)$. There was a significant difference in initial PDC between those who became adherent after the mailed letter and those who did not $(\mathrm{OR}=39.283 ; 95 \% \mathrm{CI}=2.764-558.363$; $P=0.007$ ). Region and generic medications were not identified as significant predictors of adherence in this model.

\section{Discussion}

The present study demonstrated a $24.1 \%$ increase in adherence following a pharmacy intervention of a single mailed letter sent to a population of older individuals previously non-adherent to statins, ACEI/ARBs, or oral antidiabetic medications, and who were previously unreachable by telephone.

While our data did not corroborate past research suggesting higher adherence to ACEI compared to other medication classes, ${ }^{26,27}$ the overall increase of $24.1 \%$ among these specific medications targeting chronic disease prevention (statins, ACE inhibitors/ARBs, and oral antidiabetic medications) was associated with PDC at baseline, and with days' supply. The mailing strategy and medications studied appear welltargeted for effectiveness in chronic diseases given past research showing that mailed letters increased adherence to antidepressant medication by only $2 \%$ compared to controls. ${ }^{18}$ Our data also corroborate past research on the added value of multiple modes of contact at the patient, provider, and system levels; Jing et al describe that mailed letters to physicians can lower nonadherence rates from $35.6 \%$ to $30.8 \%$, with a decrease to $27.7 \%$ when patients are also mailed letters. ${ }^{19}$ Managed care organizations should consider a strategy of tailored mailings to try to reach all of their non-adherent customers in an effort to improve patient health outcomes and improve plan quality ratings.

Individuals who filled more than 30 days of medication at a time were more likely to become adherent after the mailed letter than those who filled a 30-day supply or less. Also, higher initial PDC was a significant predictor of becoming adherent after the mailed letter. These findings are consistent with past studies' findings of higher adherence rates with 90 - vs 30 -day supply. ${ }^{28,29}$ There is evidence that automatic refill programs can be properly managed in chronic disease maintenance to avoid oversupply with both 30 - and 90-day prescriptions, and that such programs are suitable for patients who have memory or transportation barriers to refilling medications at regular pharmacies. ${ }^{30}$ To improve 
medication adherence, Medicare Advantage Plans should encourage their customers and prescribers to use 90- rather than 30-day supplies of chronic medications.

\section{Limitations and strengths}

More than one-third of those who received a mailed letter (38.5\%) did not fill the specified medication within 6 months. It is a limitation of the present study that the claims data did not allow exclusions due to provider-instructed medication discontinuation or switching. Determining such cases and excluding them before mailing letters would reduce the denominator and improve effectiveness as measured by PDC, also helping target the intervention further to applicable prescribing patterns.

Valid and reliable adherence measurement using claims data has always posed a challenge in research. Use of PDC as an outcome measure carries certain limitations, including the possibility that a prescription could be filled according to schedule but not taken as prescribed. Medication event monitoring systems such as pill bottle caps or daily logs were designed to overcome this challenge, but a potential measurement bias where medications were being filled and "stockpiled" rather than taken would apply to customers using mail-order pharmacies, ${ }^{14}$ only 11 individuals (less than $2 \%$ of the analytic sample in the present study) used home delivery or mail-order pharmacies. While our data demonstrated a higher adherence rate in those using home delivery or mail-order pharmacies $(27 \%$ adherent after the letter) vs those using retail pharmacies ( $24 \%$ adherent after the letter), these counts were too small to evaluate statistical significance.

Age was significantly associated with the outcome of change in continuous PDC in the linear regression, but not for dichotomous PDC in the logistic regression. In this study, individuals previously non-adherent to statin medications showed greater responsiveness to the mailing than those previously non-adherent to ACEIs or ARBs. Conversely, one study demonstrated oral antidiabetic medication as being a significant predictor of adherence compared to ARBs and statins. ${ }^{27}$ Future research should continue to evaluate the relative effects of disease-specific factors among these chronic conditions.

There was no statistically significant medication adherence differences according to measured categories of ethnicity, copay, or pharmacy type, despite having previous literature support the association between these characteristics and medication adherence. While minorities have been shown to have lower adherence in some studies, ${ }^{31,32}$ in this analysis there was no detectable difference by race. Our data did not corroborate previous research from 2014 concluding an effect of copayment on adherence, ${ }^{13}$ but this could be due to the fact that the previous study was conducted in an exclusively veteran population.

One assumption in the present study was that each individual who was mailed a letter also received and read the letter. However, the address listed in the organization's system may have been incorrect, the letter may never have been opened, or there could have been language or literacy barriers. Also, this study analyzed only pharmacy prescription claims viewed by the Medicare Advantage Plan. If a person had multiple insurance providers or paid cash for some of their prescriptions, this would not have been captured in the analysis.

This study also assumed that each individual being prescribed these medications should be taking them every day, while some indications may utilize alternative dosing. However, this inaccuracy would be consistent across multiple time points and is also present in the CMS Part D Stars Ratings (the national federal agency plan quality rating system). To address the possibility that individuals may have discontinued or switched medication throughout the year, a sub-analysis of those who filled the medication at least once after the mailed letter was performed. As shown in Table 4 as well as Tables S1 and S2, the results were robust to varying this assumption. Another limitation of this study was its pre-post design, which led to limited causal inference. ${ }^{33}$ However, claims data investigations that require continuous enrollment to be included in the analytic sample are important in planning and allocating resources for improving quality of care and designing prospective randomized studies.

In quantifying improvements in adherence among Medicare Advantage participants using PDC and pharmacy claims data, this study maximized health plan data resources and population health analytics to identify a mailing intervention for further use and investigation.

\section{Conclusion}

A single mailed letter significantly improved medication adherence by $24.1 \%$ in a non-adherent population that could not be reached previously by telephone. To our knowledge, this is the first study to analyze the targeted intervention concomitantly with multiple individual-, plan-, and system-level characteristics associated with improved medication adherence in chronic diseases. Future studies should incorporate a control group, and track associated health outcomes as 
a measure of intervention effectiveness. As a health plan seeking to improve its customers' well-being and outcomes, teams within Cigna are continuing to utilize targeted mailing interventions to help improve medication adherence.

\section{Acknowledgments}

This work was funded by Cigna. Some of these results have been submitted for presentation as a peer-reviewed poster at the American Managed Care \& Specialty Pharmacy Annual Meeting in April 2016. The abstract was awarded a bronze medal and appears in the conference proceedings.

\section{Author contributions}

Esse, Abughosh, Serna, and Mann contributed to the study design. Mann collected the data. Abughosh, Esse, Castel, and Mann performed the data interpretation. Mann wrote the manuscript, and all authors contributed to data analysis, drafting and revising the article, gave final approval of the version to be published, and agree to be accountable for all aspects of the work.

\section{Disclosure}

At the time the work was conducted, Mann, Esse, Castel, and Serna were all full-time employees of Cigna Corporation or its operating subsidiaries. The authors report no other conflicts of interest in this work.

\section{References}

1. Ho PM, Rumsfeld JS, Masoudi FA, et al. Effect of medication nonadherence on hospitalization and mortality among patients with diabetes mellitus. Arch Intern Med. 2006;166(17):1836-1841.

2. Wu JR, Frazier SK, Rayens MK, Lennie TA, Chung ML, Moser DK. Medication adherence, social support, and event-free survival in patients with heart failure. Health Psychol. 2013;32(6):637-646.

3. Zhao Y, Zabriski S, Bertram C. Associations between statin adherence level, health care costs, and utilization. J Manag Care Spec Pharm. 2014; 20(7):703-713.

4. Roebuck MC, Liberman JN, Gemmill-Toyama M, Brennan TA. Medication adherence leads to lower health care use and costs despite increased drug spending. Health Aff. 2011;30(1):91-99.

5. Sokol MC, Mcguigan KA, Verbrugge RR, Epstein RS. Impact of medication adherence on hospitalization risk and healthcare cost. Med Care. 2005;43(6):521-530.

6. Jha AK, Aubert RE, Yao J, Teagarden JR, Epstein RS. Greater adherence to diabetes drugs is linked to less hospital use and could save nearly \$5 billion annually. Health Aff. 2012;31(8):1836-1846.

7. Centers for Medicare \& Medicaid Services, Center for Medicare. Medicare 2015 Part C \& D Star Rating Technical Notes; 2015;1-118. Available from: https://www.cms.gov/medicare/prescription-drug-coverage/ prescriptiondrugcovgenin/performancedata.html. Accessed January 3, 2016.

8. Halava H, Korhonen MJ, Huupponen R, et al. Lifestyle factors as predictors of nonadherence to statin therapy among patients with and without cardiovascular comorbidities. CMAJ. 2014;186(12):E449-E456.
9. Easthall C, Taylor N, Bhattacharya D. Barriers to medication adherence in patients prescribed medicines for the prevention of cardiovascular disease: a conceptual framework. Int J Pharm Pract. 2018.

10. Brennan TA, Dollear TJ, Hu M, et al. An integrated pharmacy-based program improved medication prescription and adherence rates in diabetes patients. Health Aff. 2012;31(1):120-129.

11. Spence MM, Makarem AF, Reyes SL, et al. Evaluation of an outpatient pharmacy clinical services program on adherence and clinical outcomes among patients with diabetes and/or coronary artery disease. J Manag Care Spec Pharm. 2014;20(10):1036-1045.

12. Davis EM, Packard KA, Jackevicius CA. The pharmacist role in predicting and improving medication adherence in heart failure patients. J Manag Care Spec Pharm. 2014;20(7):741-755.

13. Watanabe JH, Kazerooni R, Bounthavong M. Association of copayment with likelihood and level of adherence in new users of statins: a retrospective cohort study. J Manag Care Pharm. 2014;20(1): $43-50$.

14. Iyengar RN, Balagere DS, Henderson RR, Lefrancois AL, Rabbitt RM, Frazee SG. Association between dispensing channel and medication adherence among medicare beneficiaries taking medications to treat diabetes, high blood pressure, or high blood cholesterol. J Manag Care Spec Pharm. 2014;20(8):851-861.

15. Márquez Contreras E, Vegazo García O, Martel Claros N, et al. Efficacy of telephone and mail intervention in patient compliance with antihypertensive drugs in hypertension. ETECUM-HTA study. Blood Press. 2005;14(3):151-158.

16. Walker EA, Shmukler C, Ullman R, Blanco E, Scollan-Koliopoulus M, Cohen HW. Results of a successful telephonic intervention to improve diabetes control in urban adults: a randomized trial. Diabetes Care. 2011;34(1):2-7.

17. Solomon DH, Iversen MD, Avorn J, et al. Osteoporosis telephonic intervention to improve medication regimen adherence: a large, pragmatic, randomized controlled trial. Arch Intern Med. 2012;172(6): 477-483.

18. Hoffman L, Enders J, Luo J, Segal R, Pippins J, Kimberlin C. Impact of an antidepressant management program on medication adherence. Am J Manag Care. 2003;9(1):70-80.

19. Jing S, Naliboff A, Kaufman MB, Choy M. Descriptive analysis of mail interventions with physicians and patients to improve adherence with antihypertensive and antidiabetic medications in a mixed-model managed care organization of commercial and Medicare members. J Manag Care Pharm. 2011;17(5):355-366.

20. Block G, Azar KM, Romanelli RJ, et al. Diabetes prevention and weight loss with a fully automated behavioral intervention by email, web, and mobile phone: a randomized controlled trial among persons with prediabetes. J Med Internet Res. 2015;17(10):e240.

21. Choudhry NK, Shrank WH, Levin RL, et al. Measuring concurrent adherence to multiple related medications. Am J Manag Care. 2009;15(7): 457-464.

22. Steiner JF, Prochazka AV. The assessment of refill compliance using pharmacy records: methods, validity, and applications. J Clin Epidemiol. 1997;50(1):105-116.

23. Choudhry NK, Glynn RJ, Avorn J. Untangling the relationship between medication adherence and post-myocardial infarction outcomes: medication adherence and clinical outcomes. Am Heart $J$. 2014;16758(1):51e55.

24. Osterberg L, Blaschke T. Adherence to medication. NEngl J Med. 2005; 353(5):487-497.

25. Schmittdiel JA, Nichols GA, Dyer W, Steiner JF, Karter AJ, Raebel MA. Health care system-level factors associated with performance on Medicare STAR adherence metrics in a large, integrated delivery system. Med Care. 2015;53(4):1-337.

26. Viana M, Laszczynska $\mathrm{O}$, Mendes S, et al. Medication adherence to specific drug classes in chronic heart failure. J Manag Care Spec Pharm. 2014;20(10):1018-1026. 
27. Yeaw J, Benner JS, Walt JG, Sian S, Smith DB. Comparing adherence and persistence across 6 chronic medication classes. J Manag Care Pharm. 2009;15(9):728-740.

28. Leslie RS, Gilmer T, Natarajan L, Hovell M. A multichannel medication adherence intervention influences patient and prescriber behavior. J Manag Care Spec Pharm. 2016;22(5):526-538.

29. Taitel M, Fensterheim L, Kirkham H, Sekula R, Duncan I, Supply Medication Days'. Medication days' supply, adherence, wastage, and cost among chronic patients in Medicaid. Medicare Medicaid Res Rev. 2012;2(3)

30. Matlin OS, Kymes SM, Averbukh A, et al. Community pharmacy automatic refill program improves adherence to maintenance therapy and reduces wasted medication. Am J Manag Care. 2015;21(11):785-791.
31. Lauffenburger JC, Robinson JG, Oramasionwu C, Fang G. Racial/ Ethnic and gender gaps in the use of and adherence to evidence-based preventive therapies among elderly Medicare Part D beneficiaries after acute myocardial infarction. Circulation. 2014;129(7):754-763.

32. Zhang Y, Baik SH. Race/Ethnicity, disability, and medication adherence among medicare beneficiaries with heart failure. J Gen Intern Med. 2014;29(4):602-607.

33. Campbell DS J. Experimental and quasi-experimental designs for research. Chicago, IL: Rand-McNally; 1963. 


\section{Supplementary materials}

Table SI Sub-analysis of letter recipients with medication filled after letter was sent $(n=284)$

\begin{tabular}{|c|c|c|}
\hline & Beta (standard error) & $P$-value \\
\hline Language of letter & $-0.009(0.044)$ & 0.834 \\
\hline Age & $-0.001(0.002)$ & 0.478 \\
\hline Gender & $-0.00 \mathrm{I}(0.033)$ & 0.980 \\
\hline Ethnicity & $-0.030(0.021)$ & 0.153 \\
\hline Region: Texas vs out of state & $0.045(0.022)$ & 0.045 \\
\hline Low income subsidy eligibility & $0.043(0.037)$ & 0.251 \\
\hline Medication category & $-0.007(0.022)$ & 0.755 \\
\hline Generic vs brand & $-0.060(0.077)$ & 0.436 \\
\hline Day supply & $0.144(0.034)$ & $<0.001$ \\
\hline Copay & $-0.001(0.003)$ & 0.802 \\
\hline Pharmacy type & $0.032(0.104)$ & 0.762 \\
\hline
\end{tabular}

Abbreviation: PDC, proportion of days covered.
Table S2 Sub-analysis of letter recipients with medication filled after letter was sent $(n=284)$

Logistic regression analysis of adherence as measured by 6-month PDC of at least $80 \%$ after the mailed letter

\begin{tabular}{|c|c|c|}
\hline & OR $(95 \% \mathrm{CI})$ & $P$-value \\
\hline \multicolumn{3}{|l|}{ Language of letter } \\
\hline English & Reference & Reference \\
\hline Spanish & $0.948(0.418-2.148)$ & 0.898 \\
\hline \multicolumn{3}{|l|}{ Age } \\
\hline Age, years & $1.001(0.975-1.028)$ & 0.939 \\
\hline \multicolumn{3}{|l|}{ Gender } \\
\hline Female & Reference & Reference \\
\hline Male & $1.045(0.604-1.81 \mathrm{I})$ & 0.874 \\
\hline \multicolumn{3}{|l|}{ Ethnicity } \\
\hline White & Reference & Reference \\
\hline Hispanic & $0.642(0.266-1.553)$ & 0.326 \\
\hline African-American & $0.743(0.344-1.603)$ & 0.449 \\
\hline Asian & - & 0.987 \\
\hline \multicolumn{3}{|l|}{ Region of Texas } \\
\hline Out of Texas & Reference & Reference \\
\hline West & $0.524(0.088-3.142)$ & 0.480 \\
\hline East & $0.912(0.181-4.603)$ & 0.911 \\
\hline \multicolumn{3}{|c|}{ Low income subsidy eligibility } \\
\hline No & Reference & Reference \\
\hline Yes & $1.667(0.888-3.130)$ & 0.112 \\
\hline \multicolumn{3}{|l|}{ Medication category } \\
\hline Statin & Reference & Reference \\
\hline ACEI/ARB & $0.777(0.425-1.422)$ & 0.413 \\
\hline Oral antidiabetic & $0.743(0.341-1.619)$ & 0.455 \\
\hline \multicolumn{3}{|l|}{ Generic vs brand } \\
\hline Generic & Reference & Reference \\
\hline Brand & $0.305(0.08 \mathrm{I}-\mathrm{I} .147)$ & 0.079 \\
\hline \multicolumn{3}{|l|}{ Day supply } \\
\hline 30 days or less & Reference & Reference \\
\hline$>30$ days & $2.743(1.514-4.970)$ & 0.001 \\
\hline \multicolumn{3}{|l|}{ Copay } \\
\hline Copay, \$ & $1.021(0.98 I-1.064)$ & 0.303 \\
\hline \multicolumn{3}{|l|}{ Pharmacy type } \\
\hline Retail & Reference & Reference \\
\hline Mail order & $0.845(0.154-4.649)$ & 0.847 \\
\hline
\end{tabular}

Abbreviations: ACEl, angiotensin-converting enzyme inhibitor; ARB, angiotensin receptor blocker; PDC, proportion of days covered.
Patient Preference and Adherence

\section{Publish your work in this journal}

Patient Preference and Adherence is an international, peer-reviewed, open access journal that focuses on the growing importance of patient preference and adherence throughout the therapeutic continuum. Patient satisfaction, acceptability, quality of life, compliance, persistence and their role in developing new therapeutic modalities and compounds to optimize clinical outcomes for existing disease states are major areas of interest for the journal. This journal has been accepted for indexing on PubMed Central. The manuscript management system is completely online and includes a very quick and fair peer-review system, which is all easy to use. Visit http://www. dovepress.com/testimonials.php to read real quotes from published authors. 